\title{
Leitura e escrita no governo de homens e coisas. Província de São Paulo - Século XIX
}

\author{
Reading and writing in governing men and things. \\ Province of São Paulo - 19th century \\ Lectura y escrita en el gobierno de hombres y cosas. \\ Provincia de São Paulo - Século XIX \\ Celia Maria Benedicto Giglio \\ Universidade Federal de São Paulo (Brasil) \\ https://orcid.org/0000-0002-6627-5459 \\ http://lattes.cnpq.br/1678240654096420 \\ celia.giglio@unifesp.br
}

\section{Resumo}

O artigo apresenta considerações preliminares de investigação sobre os usos da leitura e da escrita pelo Estado a partir de estudo que mapeou o desenvolvimento de práticas educativas disseminadas na Província de São Paulo entre 1836-1880. Privilegiando como fonte e objeto de estudo os relatórios dos presidentes da Província de São Paulo e com base na história cultural, mais especificamente nos escritos de Roger Chartier, apresentamos aspectos que apontam para os usos da leitura e da escrita como imprescindíveis no governo de homens e coisas. A partir da descrição de três eventos: a formação da estatística da província durante o período, a introdução do inquérito policial pela Reforma Judiciária de 1871 e o uso da leitura e da escrita na regeneração moral de sentenciados, demonstramos haver solo fértil para aprofundar o exame da escrita do Estado e considerarmos tal hipótese em investigações futuras.

Palavras-chave: História da educação. Leitura e escrita. Escrita do Estado. Província de São Paulo. História Cultural. 


\begin{abstract}
This paper presents preliminary research considerations about the use of reading and writing by the State, based on a study that mapped the development of educational practices disseminated in the Province of São Paulo between 1836 and 1880. We concentrated on reports of the presidents of the Province of São Paulo as source and object of study. In addition, based on cultural history, more specifically in the writings of Roger Chartier, we present aspects that point to the uses of reading and writing as essential in governing men and things. We used the description of three events, namely, the formation of provincial statistics during the period, the introduction of the police inquiry by the Judicial Reform of 1871, and the use of reading and writing in the moral regeneration of sentenced persons, to show there is promising evidence to deepen the examination of State writings and to consider such hypothesis in future investigations.
\end{abstract}

Keywords: History of education. Reading and writing. State writing. Province of São Paulo. Cultural History.

\title{
Resumen
}

El artículo presenta consideraciones preliminares de investigación sobre los usos de la lectura y la escritura por el Estado a partir de un estudio que mapeó el desarrollo de prácticas educativas diseminadas en la Provincia de São Paulo entre 1836-1880. Privilegiando como fuente y objeto de estudio los informes de los presidentes de la Provincia de São Paulo y con base en la historia cultural, más específicamente en los escritos de Roger Chartier, presentamos aspectos que apuntan a los usos de la lectura y de la escritura como imprescindibles en el gobierno de hombres y cosas. A partir de la descripción de tres eventos: la formación de la estadística de la provincia durante el período, la introducción de la encuesta policial por la Reforma Judicial de 1871 y el uso de la lectura y la escritura en la regeneración moral de sentenciados, demostramos haber suelo fértil para profundizar el examen de la escritura del Estado y considerar tal hipótesis en investigaciones futuras.

Palabras clave Historia de la educación. Lectura y escritura. Escrita del Estado. Provincia de San Pablo. Historia Cultural. 


\section{Introdução}

A pesquisa em História da Educação faz uso de um conjunto extenso de fontes primárias: explora arquivos públicos, privados, faz uso da história oral, explora jornais e outros impressos; sua fonte privilegiada são os textos escritos em vários suportes e de origens variadas.

As fontes governamentais compõem um acervo especial para a história de maneira geral e para a história da educação de modo particular, por permitirem o acesso não apenas aos conteúdos convencionados como referidos à instrução ou à educação pública, mas também permitem uma apreciação em contexto, dando a ver no conjunto documental em que se apresentam a própria constituição do campo educativo mergulhado nos acontecimentos em cada época. Se por um lado as fontes governamentais, em razão de sua preservação privilegiada, podem ser vistas como restritivas, por outro lado elas nos facultam uma entrada singular para o exame do campo da educação, nos desafiando quanto aos usos que delas fazemos e ao quanto podemos as tensionar, interrogando os textos não apenas como fontes, mas também como objetos. ${ }^{1}$

Nesse artigo apresentamos apontamentos a partir do exercício de tomar por fonte e objeto de pesquisa os Relatórios dos Presidentes da Província de São Paulo compreendidos no período de 1836 a 1880, colocando foco nos aspectos que envolvem a leitura e a escrita como ferramentas de governo, buscando destacar seus usos e formas de apropriação pelo Estado, localizadas na mecânica de governar a Província no contexto de uma população iletrada.

Levantamos a hipótese de uma possível dimensão de interferência dessa imprescindibilidade nos modelos de ensino escolar da leitura e da escrita, conferindo a eles poderes que normalizam as práticas escolares em favor da ordem estabelecida e preparam para a obediência. Assim, a relação entre a proliferação de textos oficiais produzidos pelo Estado no século XIX - tais como leis, normas, regulamentos, relatórios, e as muitas demandas vindas da formação da estatística no império - e as necessárias competências de leitura e escrita por parte de seus agentes, conformam um cenário que provoca considerar, como campo de investigação, a escrita do Estado como artefato cultural que opera relações de poder para muito além de seus conteúdos prescritivos.

Chartier (1990, p.218) ao tratar da construção do Estado moderno na Europa ocidental e das formas culturais que caracterizam este Estado aborda a presença da escrita, apresentando três grandes rupturas na forma como o Estado dá a conhecer as suas vontades ou registra a de seus súditos: a que substitui a declaração oral pela fixação escrita, a que substitui o recurso ao notário pelo desenvolvimento das chancelarias e a que faz recuar o manuscrito perante o texto impresso.

Esta última ruptura oferece uma chave de entrada importante para pensarmos a proliferação de ordens, leis, regulamentos e prescrições de práticas de governo, presentes entre nós durante o século XIX e as correspondentes demandas de leitura e escrita desde o Estado. Este recuo do manuscrito em favor dos textos impressos, segundo Chartier, altera a escala de circulação dos documentos oficiais e dos demais escritos. Acompanhando a produção sistemática dos relatórios dos governos provinciais de São Paulo e de modo esporádico os relatórios ministeriais e de outras províncias e países, podemos afirmar que esta circulação dos impressos foi intensa entre as províncias, pois aparecem citados e comentados nos relatórios, podendo neles serem encontrados trechos copiados de relatórios de outras províncias.

\footnotetext{
${ }^{1}$ As fontes aqui citadas estão disponíveis no sítio http://ddsnext.crl.edu/brazil Center for Research Libraries. O Projeto Latino-Americano de Materiais (LAMP) do Centro de Bibliotecas de Pesquisa (CRL) digitalizou documentos em série do poder executivo emitidos pelo governo nacional do Brasil entre 1821 e 1993, e por seus governos provinciais desde os primeiros disponíveis para cada província até o final da primeira República em 1930. Informações adicionais sobre este projeto estão disponíveis nas páginas da Web da LAMP.
} 
Notícias do progresso das instituições em outras províncias e em outros países geralmente nominados como "nações mais cultas" - também surgem nos relatórios em operações de comparação do grau de adiantamento na condução dos negócios da província. Não raro se pode encontrar trechos transcritos dando a conhecer formas de organização da administração pública nos campos de maior interesse, como por exemplo: os modelos correcionais modernos, modos de administração da justiça, de organização administrativa da instrução pública, métodos de ensino, modelos de inspeção da instrução pública dentre outros. Ilustrando essa afirmação, podemos destacar o uso de exemplos de medidas adotadas em outros Estados para solucionar problemas semelhantes aos nossos quando à obrigatoriedade do ensino pelas famílias: “[...] As grandes nações que devem ser nossos guias compelem sob multas as famílias a mandar os filhos a aprender a ler e escrever" $(1864)^{2}$

Desse modo, a circulação dos impressos produz também a circulação de modelos de condução dos vários ramos da administração, além de impactar as formas dos registros que constroem espécies de protocolos de comunicação e de transmissão de informações escritas, estabelecendo um padrão comum que pode ser encontrado ao examinarmos relatórios governamentais de outros países da América do Sul e da Europa. Destacamos aqui a circulação desses impressos governamentais como portadores da função indutora de políticas, tanto no âmbito internacional quanto local.

Afirma Chartier (1990, p.219) que "Medir a produção da escrita de Estado implica que se meçam igualmente as competências culturais das populações, agentes ou súditos do Estado, que exercem ou apreendem o poder de comando e de justiça por meio de textos que se destinam a ser lidos." Temos aqui uma provocação suficiente para investigar a proliferação de escritos do Estado ao longo do século XIX e os possíveis impactos deste modelo de escrita na conformação das práticas de leitura que se desenvolvem nas escolas de primeiras letras; este exercício poderá dar visibilidade a práticas de escolarização que nos conduzem a busca dos sentidos da leitura e da escrita escolar como práticas expostas a interferências mais gerais e não protegidas das disputas políticas que tentam instaurar a ordem e pacificar as populações.

Nesse sentido, e como incursão inicial, consideramos essa hipótese inspiradora para investigar a escrita do Estado e as práticas de leitura por ele demandadas.

\section{Artefatos culturais do poder}

A produção escrita do Estado imperial brasileiro pode ser considerada um artefato da cultura governamental que dá visibilidade ao processo de institucionalização de mecanismos de poder nos quais as maneiras de ler e os modos de escrever assumem funções inequívocas de construção e manutenção da ordem instituída.

Reencontrar as práticas de leitura na espessura destes artefatos culturais de governo indica um necessário retorno aos impressos com um itinerário específico que possibilite interrogar os textos no sentido proposto por Chartier quanto às competências culturais dos agentes aos quais se destinam, mas também atento às tensões e subversões reveladas pelos próprios textos. Nosso exercício aqui foi o de revisitar a série de relatórios de presidentes da província de São Paulo no período de 1836 a 1880 e destacar indícios destas práticas de leitura e escrita que, localizadas fora da escola, podem ter produzido demandas disseminadas a serem capturadas por um modelo escolar que se pretendia fosse um modelo de civilização exemplar.

Destinados ao poder legislativo e à transmissão do cargo a outro presidente, os relatórios se configuram como um meio de organização e ordenação, um dispositivo de controle da administração sobre a vida dos cidadãos e do próprio Estado. Os textos

\footnotetext{
${ }^{2}$ Relatório sobre a Instrução Pública de S. Paulo em 1864 apresentado ao Ilm. E Exm. Snr. Conselheiro João Chrispiniano Soares Presidente da Província pelo Inspetor Geral da Mesma Instrução Pública Diogo de Mendonça Pinto.
} 
produzidos nesta operação basicamente nascem da observação, da reunião e transmissão de informações, da organização de uma estatística, necessária à atuação do governo em larga escala e que permitam deslocamentos estratégicos nas formas de conduzir os fenômenos que envolvem a população da província.

Nesta série de relatórios podemos verificar a tensão que anuncia um processo de transição nos modos de governar próprias do estado patrimonial em que o governo, apoiado em relações de fidelidade apenas já não basta para ordenar o social e as ordens escritas assumem cada vez mais os espaços de exercício do poder. O movimento de especialização das instituições ao longo do século XIX e as regulações necessárias aos controles dos vários ramos de atuação pública do Estado nas Províncias fazem multiplicar a edição de regulamentos a serem lidos e apreendidos para conformar as práticas, especialmente a partir de 1850, ano em que localizamos a criação da Repartição da Instrução Pública na Província e a rearticulação de outra série de serviços já estabelecidos - como os Seminários de Educandos, Colégios privados confessionais, Internatos e Liceus - que passam a compor uma rede a ser observada e regrada com maior rigor.

Não apenas o ramo da instrução pública se especializa; outras áreas de atuação passam a ser alvo de regulamentação ou de terem cada vez mais detalhadas suas normas de funcionamento. O campo da saúde pública no período constitui outro exemplo, com a criação de estruturas centrais de controle sobre a vacinação; os recolhimentos, asilos, prisões, hospitais e outras agências receberão novo impulso no que tange à sofisticação dos modos de controle, recebendo regulamentos que obrigarão a registros constantes de seu movimento.

Tomados como objetos, estes impressos se configuram como extensão e presença do soberano em todas as províncias do império. Regrados, eles mesmos, a partir da dinâmica de governo estabelecida pela Constituição Política do Império, apresentam dispositivos de ordenação dos discursos e de adequação dos textos que oferecem indícios importantes para a percepção das tensões em torno dos modos de governar a província.

O exame sistemático dos relatórios revela a incorporação de aspectos resultantes das alterações advindas da especialização das instituições, de um movimento de racionalização do qual resulta a ampliação do tratamento dos negócios da província, materializados num conjunto de informações que aparecem de modo agregado; apensados ao relatório principal do presidente, outros relatórios especializados de várias instituições surgem como anexos e estes, por sua vez, não raro podem também apresentar anexos com função semelhante e contornos de um hipertexto. Até meados dos anos de 1870, a presença de agentes públicos que atuam como extensão do Presidente e do próprio Estado é crescente e mediada pela edição de normas, regulamentos e práticas de inspeção (GIGLIO, 2001, p.28).

Nesse quadro, os impressos governamentais prescritivos - tais como as leis e os regulamentos - e suas consequentes demandas de controle mediadas por registros escritos, podem oferecer de modo singular um contexto social de leitura que sugere considerar a relação "escrita e leitura" no formato da "ordem e obediência"; trata-se de um conjunto de textos que circulam em espaços específicos e operam estrategicamente de modo a apagarem a textualidade para produzir, na prática, comportamentos ou condutas específicas. No espaço de apagamento da textualidade ganha visibilidade o poder do Estado, moldando um tipo de leitura que poderíamos nomear de leitura reverência capaz de, pelos signos próprios, diferenciar e identificar a escrita do Estado, conferindo a ela autoridade permanente.

Outra função dos impressos nesse cenário é a de organizar redes de controle e instituir figuras de autoridade que irão compor uma fórmula geral de exercício de vigilância que alia à palavra escrita o olhar de agentes - inspetores - que exercem seu poder apoiados nos textos legais e regulamentos.

À escrita deve corresponder uma leitura vigilante e cumpridora das ordens e o olhar, em geral desses inspetores, ocupará os espaços de rompimento da ordem escrita estendendo a 
autoridade física do Estado e tornando visíveis resistências que tornam-se, por sua vez, matéria para a necessária revisão desses mesmos textos prescritivos que terão por fim recompor a ordem - caso típico da edição e revisão de regulamentos em diferentes âmbitos e com graus de especificidade variados. Acompanhar o movimento de constituição das instituições nesse corpus documental a partir das narrativas ordinárias e da edição de regulamentos permite constatar a evolução de uma rede complexa de fluxos de poder ${ }^{3}$ e nessa rede a leitura e a escrita tem papel fundamental.

Vinculando um conjunto de dispositivos de controle complexos, habilita-se o trânsito de um governo realizado pelo predomínio do oral sobre o escrito para o seu contrário, com a proliferação de modos de gerir a partir de regras escritas, normas, leis, do controle de práticas administrativas que estão assentadas sobre os registros escritos - fonte de informações para o permanente desenvolvimento de estratégias de governo dos homens e das coisas. A leitura e a escrita são saberes imprescindíveis na constituição das práticas governamentais do século XIX, são veículos de manutenção da ordem e promotores da civilização.

\section{A leitura e a escrita como instrumentos de governo}

A transição de um modo de governar e administrar do predomínio do oral para o escrito, corresponde a um processo que instaurou a escrita como condição de institucionalização do Estado, processo que exigiu de modo crescente um corpo de funcionários capazes de manejar informação escrita, exercer um tipo de leitura competente e produzir informação escrita.

A transição nos modos de governar significou também a instituição de novas tecnologias de governo que permitiram transitar de um modelo de vigilância paternal sobre a província para um modelo informado pela ciência. A estatística é esta tecnologia, "a sciencia dos factos sociaes" que permitiu ao governo conhecer em nova escala o seu território. Assim registra o relatório do Presidente da Província de São Paulo em 1852:

Como se pode legislar, e administrar sem uma Estatística? No exercício de vossas funcções importantes sentireis a mesma dificuldade, que, como administrador, tenho sentido, embaraçado á cada passo pela ignorancia dos factos, os quaes alias registrados, comparados, observados e moralizados habilitarião para legislar e administrar com certeza, e não vagamente, com conhecimento de causa, e não por informações fundadas em dados, que pela anciedade e urgencia da ocasião são mal colligidos, falsos, ou inexatos.(Sic) ${ }^{4}$

A imagem do Estatístico como um novo geômetra é tratada por Jacques Revel ao traçar o movimento de formulação de uma Estatística ocorrido na França na primeira metade do século XIX, como movimento de domínio sobre o território, como problema político e mobilização contra as ameaças internas e externas ao Estado.

\footnotetext{
${ }^{3}$ A inspeção na Instrução Pública é parte de uma organização piramidal instituída na Província e certamente identifica um "chefe", um ponto central, porém é o todo que produz "poder" e distribui os indivíduos nesse campo permanente e contínuo. A extensão desta tecnologia para outros campos da administração, exemplificam a rede de relações de cima abaixo, mas também de baixo para cima e lateralmente, como numa rede que sustenta o conjunto e o perpassa de efeitos de poder que se apoiam uns sobre outros: fiscais permanentemente fiscalizados. Foucault. Vigiar e Punir p.148.

${ }^{4}$ Discurso com que o Ilustríssimo e Excelentíssimo Senhor Dr. José Thomaz Nabuco d'Araujo, presidente da província de São Paulo, abiu a Assembleia Legislativa Provincial no dia 1.o de maio de 1852. São Paulo, na Typ. do Governo arrendada por Antonio Louzada Antunes, 1852.
} 
Revel (1998, p.103-158) chama a atenção quanto à efervescência estatística da primeira metade do século XIX e para o fato de que esta efervescência não está circunscrita ao âmbito de iniciativas públicas, ao contrário, ela aparece multiplicada em experiências individuais e locais por particulares interessados na utilidade social e nas aplicações práticas. "Um pouco por toda parte, se espera que a estatística forneça os elementos de um estudo geral da sociedade. [...] "O estatístico, como novo geômetra, torna-se com o médico, outro rosto da ciência organizadora, o grande especialista social capaz de medir todas as coisas."

Nestes impressos a necessidade da estatística para conhecer o império está presente desde a década de 1830, no entanto, formular uma estatística implicou a construção de redes de informantes, levando a um processo de diferenciação crescente tanto das ações quanto em relação ao estabelecimento de padrões de observação, classificação, formas de registro, protocolos, enfim, que possibilitassem organizar o que estava disperso e dar visibilidade ao que talvez estivesse oculto.

Deste movimento de aperfeiçoamento da estatística podemos inferir quais competências de leitura e escrita se espera dos agentes do Estado, a escala de controles necessários para a obtenção das informações. Podemos afirmar que na série de impressos analisados e, a partir dos mapas estatísticos contidos nos relatórios, ocorreu um movimento de disciplinamento dos registros institucionais por meio da adoção de modelos impressos, regulamentos e vigilância direta. Este é um processo que implicou competências de leitura e escrita especiais, que concretizaram os pares: escrita-ordem e leitura-obediência, portanto competências relacionadas não apenas ao domínio dos códigos, mas que incorporaram a reverência aos textos. Da recolha das informações à elaboração das estatísticas há resistências narradas nestes artefatos materializadas pelos registros de reclamos sobre o não envio de relatórios, de informações, rompendo a cadeia de transmissão de informações.

Em 1855, um regulamento estabelece as normas de organização e classificação para o trabalho do encarregado da estatística da Província, com base na Lei Provincial no 30 de 10 de maio do mesmo ano, detalhando os dados a serem verificados pelo encarregado da estatística da Província, prevendo o artigo $3^{\circ}$ do regulamento que, além das penas estabelecidas em lei provincial, "o Presidente da Província poderá impor aos que por negligencia não cumprirem as ordens relativas a organização da Estatística da província a multa de cem a duzentos mil réis". 5 A presença deste artigo é indicativa das resistências e tensões que permearam tanto a produção de informação escrita quanto a transmissão destas mesmas informações, frustrando uma mecânica concebida no formato de redes.

Paulatinamente os relatórios apresentam aspectos da formação dessa Estatística da Província a serem aperfeiçoados e destacam a necessidade de especialização dessa atividade a partir dos usos de dados e informações tidas como não satisfatórias em quantidade, qualidade e temporalidade, essa última relativa a agilidade na confecção das mesmas para intervir na realidade e medir a evolução dos acontecimentos na província, indiciando a transição de um modelo de governo paternal para outro informado pela ciência, tornando mais complexas e especializadas as ações dos agentes do Estado.

A necessidade da produção de uma estatística oficial pelos governos foi internacional. Segundo Botelho (2005, p.331)

a necessidade da estatística oficial para o governo dos povos era universalmente proclamada, e as nações que procuravam caminhar na vanguarda da civilização consideravam-na um dos ramos importantes do serviço público. Nos Congressos Internacionais de Estatística estavam

\footnotetext{
${ }^{5}$ Documentos com que o Ilustríssimo e Excelentíssimo Senhor Dr. José Antonio Saraiva, Presidente da Província de S. Paulo, instruiu o relatório da abertura da Assembleia Legislativa Provincial no dia 15 de fevereiro de 1855. S. Paulo, Typ. 2 de Dezembro de Antonio Louzada Antunes, 1855.
} 
sendo estabelecidas regras recomendadas a todos os povos civilizados: "a estatística oficial já não é apenas uma necessidade das nações, é moralmente um quase compromisso internacional, que um dia há de ser regulado por convenções entre os Estados no interesse da civilização."

Tanto o efeito desse movimento mais geral de estabelecimento e regramento de estatísticas oficiais, quanto a circulação de impressos oficiais de governos ministeriais e provinciais entre os países e no interior das províncias, revelam o papel da leitura e da escrita na construção dessa civilidade almejada. No campo da instrução pública há evidências de iniciativas europeias de levantamento de dados para a confecção de um Mapa Mundi da Instrução Popular em 1880, cujos impressos para coleta de informações estão redigidos em várias línguas, fato que sugere inciativas do mesmo cunho realizadas também em outras áreas de governo durante o período. ${ }^{6}$

As cadeias de transmissão das informações na construção da estatística são também uma arquitetura que distribui os leitores numa hierarquia de competências de leitura e escrita que podem ter conformado modelos de leitura destinados a públicos distintos. Caberia aqui aprofundar a análise sobre as práticas escolares de leitura e verificar se existem impactos destas competências esperadas pela escrita do Estado nos modos de ensinar a leitura e a escrita nas escolas, associando os diferentes modos de ensinar aos diferentes públicos a que se destinam.

\section{O governo pela palavra: ler, entender, executar.}

Tomaremos aqui o caso da força pública e as competências de leitura que passam a ser exigidas destes agentes do Estado em decorrência das práticas de governo e administração da justiça. A Reforma Judiciária de 1871 que instituiu o inquérito policial como procedimento de investigação criminal preliminar é um exemplo importante para considerarmos as novas demandas de leitura e escrita, voltadas aos agentes que atuavam para a então chamada Tranquilidade Pública.

Tendo por função não a da produção da acusação de uma pessoa, mas sim a de reunir provas dos fatos, o inquérito policial exigia a adoção de condutas regradas em todo percurso da ação policial: "O inquérito policial consiste em todas as diligencias necessárias para o descobrimento dos fatos criminosos, de suas circunstancias e dos seus autores e cúmplices e deve ser reduzido a escrito"(grifo nosso). ${ }^{7}$

Segundo Rosemberg (2005 p.3), no inquérito as funções investigativas da polícia, tinham por fim reunir evidências que auxiliassem no convencimento dos juízes acerca da "verdade dos fatos" e eram lastreadas em "princípios inquisitoriais, ou seja, em fase de inquérito não havia réus, lançava-se uma suspeição contra um indivíduo que, em sede policial, não podia se defender, uma vez que não havia acusação formal."

Como estas práticas de administração da justiça - que envolvem o conhecimento da norma por meio de uma leitura competente e a capacidade de escrita - se constituem na província de São Paulo? Por um lado, encontramos nos relatórios evidências das resistências à própria instituição do inquérito policial como uma prática eficiente para a prevenção dos crimes, pois o processo implicaria em formalidades que dão a ver a ação policial como uma desvantagem, segundo o chefe de polícia em 1871, além dos problemas quanto à capacidade dos comandantes de patrulha para aplicarem as prescrições da lei.

\footnotetext{
${ }^{6}$ Esses impressos organizados como uma grande tabela foram localizados na Torre do Tombo em Lisboa no ano de 2007.

${ }^{7}$ Art. 42 do Decreto n. ${ }^{\circ} 4.824$, de 22 de 1871 que regulamenta a Lei n. ${ }^{\circ} 2.033$, de 20 de setembro de 1871. Disponível em: <http://www.planalto.gov.br/ccivil_03/decreto/historicos/dim/DIM4824.htm> Acesso em 20 de abril 2019.
} 
Prevenir os crimes, descobrir e capturar os delinquentes - é a missão principal da polícia; mas para ser realizada é indispensável força e liberdade de acção. De ambas está a polícia despojada. Querer policia ativa, enérgica e previdente, e prender a autoridade com a pêa das formalidades, é exigir milagres; e o poder de operal-os só a Deus pertence. As formalidades repellem o segredo, e este é a alma da polícia. Ella deve ver sem ser vista. (Sic)

Enquanto a policia occupar-se em fazer a descripção do lugar onde foi commettido o crime, emquanto proceder a inquéritos e os remeter ao juiz processante, e emquanto o Juiz Municipal resolver sobre a expedição da ordem de prisão, o criminoso terá tempo sobejo de buscar abrigo, onde não possa haver notoriedade de tal expedição. (Sic) ${ }^{8}$

No mesmo relatório de 1871 encontra-se a exposição do problema imposto pela nova Lei, sendo orientada a ação policial durante a noite para "colher em flagrante todos os delinquentes, a fim de não ficar presa na rede de formalidades que a lei criou para as prisões". A estratégia tinha por fim evitar a formação do inquérito pelas dificuldades enunciadas para lavrar o ato e saber enquadrar os crimes.

Quem não fôr preso em flagrante zombará da policia, porque dificilmente a acção dela poderá molestar-lhe. A esses postos podem ser recolhidos os ébrios que forem encontrados a dormir nas ruas, ou as victimas de qualquer moléstia, ou acidentes que necessitem de promptos socorros. Poderão também ser recolhidos a taes postos os indivíduos que forem presos durante a noite, e a respeito dos quaes seja mister lavrar o auto ordenado pelo art. $12 \S 3^{\circ}$ da Lei de 20 de Setembro ultimo. Os comandantes de patrulhas, que raros sabem ler, certamente não poderão lavrar tal acto, e menos saberão distinguir os crimes em que os réos se livrão soltos.(Sic)

Cabe considerarmos a demanda gerada pelo inquérito policial em termos de leitura e escrita para a força pública da época. Em 1874 a necessidade dessas competências é anunciada como exigência aos postos de comando para viabilizar as práticas da justiça: o conhecimento prático e técnico das Leis e sua aplicação, e serão enunciadas como indispensáveis também aos soldados e praças a partir daquele ano.

[...] Julgo indispensável introduzir o ensino para os soldados analfabetos, a exemplo do que se pratica na companhia de cavalaria de linha. Não preciso demonstrar as vantagens do ensino elementar para as praças de polícia, que devem conhecer a Lei para executá-la, sem excesso de atribuições. (Sic) $)^{9}$

\footnotetext{
8 Relatório da Repartição da Polícia da Província de São Paulo, 1871, p.4-22. Anexo ao Relatório apresentado à Assembleia Legislativa Provincial de São Paulo pelo Presidente da Província, o Exm. Sr. Dr. José Fernandes da Costa Pereira Junior, em 2 de fevereiro de 1872, Typ. Americana, 1871 [sic]

${ }^{9}$ Relatório apresentado ao Ilustríssimo e Excelentíssimo Senhor Dr. João Theodoro Xavier Presidente da Província de São Paulo, pelo Chefe de Polícia Joaquim José do Amaral, Juiz de Direito. Anexo ao Relatório apresentado à Assembleia Legislativa Provincial de S. Paulo, pelo Presidente da Província o Exmo. Sr. Dr. João Theodoro Xavier em 5 de fevereiro de 1874.
} 
A leitura no universo da administração da justiça também se ajusta ao par escrita ordem e leitura-obediência, ampliando-se aqui a obediência enquanto série de procedimentos que servem para serem aplicados, correspondendo a um padrão que implica o risco da nulidade da ação.

A necessidade de investimentos na formação das competências de leitura e escrita destes agentes do Estado envolvidos com a administração da justiça nasce, poderíamos dizer, do "sistema educativo" mais geral, do conjunto de situações que implicam mobilizar aprendizagens em favor da materialização da ordem.

Rogério Fernandes, historiador da educação portuguesa, ao tratar do sistema de ensino em Portugal, apresenta uma demanda vinda desse sistema educativo mais geral para o campo da instrução pública que impactará o sistema escolar português. A modernização do exército português entre finais do século XVIII e 1820 traz consigo a necessidade de alfabetização dos subalternos, gerando em várias unidades do exército, a criação de escolas militares pelo método do ensino mútuo. Essa demanda levará o exército português a fundar a primeira Escola de Habilitação de Professores em 1816 "aberta igualmente a civis, assim contribuindo para o aparecimento de docentes habilitados na aplicação do método". ${ }^{10}$

Esta notícia estimula considerar o quanto as demandas de leitura e escrita advindas do exterior da escola - no caso da Província de São Paulo para viabilizar a ação da Força Pública em conformidade com a Lei - atuam na conformação de práticas pedagógicas de organização da instrução pública e ampliação da alfabetização voltada a públicos específicos.

\section{Práticas de regeneração pela leitura}

A leitura ocupou lugar de importância nas ações de regeneração moral dos condenados durante o século XIX. Na Casa de Correção da província uma escola de primeiras letras tornou possível inicialmente a prática de leituras edificantes que na década de 70 passaram à leitura de manuais para o ensino e aperfeiçoamento dos ofícios; nas Colônias orfanológicas a alfabetização dos "menores vadios" leva ao aprendizado das artes da agricultura; nos quartéis, da instrução nas primeiras letras ao aprendizado das leis e das artes da guerra.

Considerada modelar, a Casa de Prisão com Trabalho da Província de São Paulo ${ }^{11}$ registra em seus relatórios os "motores de toda transformação moral" na Casa de Correção, resumidos em três palavras: religião, trabalho e silêncio. O ensino de primeiras letras habilitava os sentenciados a uma permanente reflexão sobre os princípios religiosos, aos quais estas leituras estavam associadas; o trabalho garantia a regularidade nas condutas e o silêncio garantia a segurança do estabelecimento, contrariando a possibilidade de quaisquer conspirações. ${ }^{12} \mathrm{O}$ modelo de correção dos sentenciados conjugava o isolamento e o trabalho em silêncio como agentes da transformação carcerária.

Para concorrer a uma completa regeneração dos condenados, serão introduzidas a religião e a instrução nas primeiras letras. Em 1855, o Presidente da Província providencia a ida de um pároco para a Casa de Correção e há iniciativas que envolvem a escola da casa que,

\footnotetext{
${ }^{10}$ Fernandes, Rogério. Gênese e consolidação do sistema educativo nacional (1820-1910). In: O sistema de Ensino em Portugal (Séculos XIX-XX). Maria Cândida Proença (Org.). Lisboa: Edições Colibri, 1998, p.23-46. Uma descrição detalhada do funcionamento da Escola Geral pode ser encontrada em Fernandes, Rogério. $O$ desafio das escolas militares. Os caminhos do ABC. Sociedade Portuguesa e Ensino das Primeiras Letras. Lisboa: Porto Editora, 1994.

${ }^{11}$ A primeira Assembleia Provincial de 1834, em São Paulo, decidiu pela criação de uma casa de prisão com trabalho, chamada posteriormente de Casa de Correção, ou Penitenciária.

${ }^{12}$ Relatório da Casa de Correção. Anexo ao Relatório com que S. Exc. O Sr.. Senador Barão de Itaúna passou a Administração da Província de S. Paulo, ao Exmo. Sr. Comendador Antonio Joaquim Rosa, $3^{\circ}$ Vice-Presidente [em 25 de abril de 1869].
} 
segundo os registros examinados, partem dos próprios presos ${ }^{13}$. A escola regida por um dos presos foi condenada pelo Diretor e suprimida - fato que leva uma Comissão Inspetora nomeada pelo presidente em 1862, a recomendar seu restabelecimento.

Há registros da proposta de fundação de uma biblioteca para uso dos sentenciados em 1876 pelo Diretor Joaquim Mariano Galvão Bueno. "O almoxarife da Penitenciária, Joaquim Mariano Galvão Bueno, que entre outras atribuições era também o responsável pelo ensino das primeiras letras aos presos analfabetos, desde 1874 , passa a diretor" [... $]^{14}$

Em 1878 a instrução primária nas instituições correcionais é apontada nos discursos oficiais como uma necessidade:

[...] A ignorancia e a ociosidade são as duas principais causas dos crimes commetidos na provincia, e na penitenciaria tem-se procurado com empenho debellar essas causas. Aos sentenciados dá-se instrucção primaria e religiosa, que os habilita ao conhecimento de seus deveres. $\mathrm{O}$ ensino de offícios mechanicos, a que são sujeitos todos os sentenciados, tambem habitua-os ao trabalho, e prepara-lhes meios de viver honestamente, quando regressarem à sociedade da qual estão sequestrados. Muito poucos são os condenados, que, quando recolhidos à penitenciária, sabem lêr, ou conhecem alguma arte: a quasi totalidade é de analphabetos e de individuos sem profissão. (Sic) ${ }^{15}$

Em várias províncias brasileiras há registros do estabelecimento de escolas de primeiras letras nas penitenciárias, fato que sugere considerar o desenvolvimento de competências de leitura específicas à regeneração do caráter como uma demanda do Estado para garantir a tranquilidade pública.

\section{Considerações finais}

As práticas educativas engendradas no exercício de governo - seja o governo do Estado, das instituições, da população ou da família -, envolveram, necessariamente novas habilidades para o exercício do poder. Se resgatarmos os usos da instrução: o ler e o escrever, verificamos que ela oferece ferramentas básicas para a continuidade de ações de outras agências que podem, a partir daí, conformar os sujeitos em suas condutas individuais e coletivas.

No âmbito mais restrito à instrução pública o período registra sucessivas aproximações à organização e ampliação dos controles sobre as instituições educativas e sobre as escolas; as condutas dos mestres e suas qualificações para ensinar, os materiais de leitura, os métodos de ensino, a liberdade dos pais em matricular e manter as crianças na escola, a inspeção do ensino e outras tantas questões tornam-se alvo da repartição da instrução pública desde 1850 .

Especificamente sobre a leitura escolar, em 1860 os relatórios registram que para a leitura no Seminário de Educandas e no Seminário de Educandos, é também utilizado nas escolas o Catecismo histórico de Fleury, traduzido pelo Conselheiro Amaral Gurgel, que na versão original apresenta além de textos, imagens, a fim de levar o leitor à compreensão do

\footnotetext{
13 “O ensino de primeiras letras vai ali regularmente progredindo, não obstante ser promovido por um mestre da mesma classe dos sentenciados. (...)”. Discurso com que o Ilustríssimo e Excelentíssimo Senhor Senador José Joaquim Fernandes Torres, Presidente da Província de S. Paulo, abriu a Assembléia Legislativa Provincial, no dia 2 de fevereiro de 1860.

${ }^{14}$ Relatório apresentado à Assembleia Legislativa Provincial de S. Paulo, pelo Presidente da Província, Sr. Dr. Sebastião José Pereira, em 2 de fevereiro de 1876

${ }^{15}$ Relatório com que o Exmo. Sr. Dr. Sebastião José Pereira passou a administração da Província ao $5^{\circ}$ VicePresidente, Monsenhor Joaquim Manoel Gonçalves de Andrade, em 16 de janeiro de 1878.
} 
sentido desejado. ${ }^{16}$. Dentre os poucos materiais de leitura distribuídos para as escolas da época, os catecismos parecem ter sido inclusive, objeto de disputa. No mesmo ano de 1860, relata o inspetor da Instrução Pública Diogo de Mendonça, que a bibliotheca da infância ganhara novo catecismo, "mandado redigir pelo Bispo Diocesano sob suas vistas para uso dos fiéis". A notícia vem acrescida de considerações sobre o editor que sugere ao Presidente da Província a adoção dele em todas as escolas como sendo o único a ser utilizado:

[...] O Editor, o cidadão Joaquim Roberto d' Azevedo Marques, que, proprietário da melhor imprensa da Provincia, já a ella tantos serviços tem prestado, concorreo em grande parte para essa obra indispensável, e immediatamente invocou o apoio d'esta Repartição á fim de obter a adopção do Livro nas casas de ensino primário. Mais tarde também officiou-me o Reverendo Vigario Geral por ordem de S. Ex ${ }^{\mathrm{a}}$. Rer.m ${ }^{\mathrm{a}}$, e o Ex.m ${ }^{\circ}$, Presidente da Província, aquelle solicitando, e este ordenando que eu expedisse as convenientes ordens á fim de ser a doutrina christã explicada nas escholas de ambos os sexos unicamente pelo referido cathecismo. A' ambos tive a honra de responder que logo que o Livro foi publicado, e pelo Editor me offerecido um exemplar, recommendeio aos Professores tanto públicos como particulares, á fim de lhe darem preferencia quando tivessem de comprar obras d'essa ordem, mas que vedar o uso de outro qualquer cathecismo não era possível por achar-se adoptado o Historico de Fleury, do qual existe grande numero de exemplares, impresso por ordem da Província para ser distribuido gratuitamente pelas escholas. $(\mathrm{Sic})^{17}$

\footnotetext{
${ }^{16}$ Relatório da Inspetoria Geral da Instrução Pública 31 de dezembro de 1860. A edição francesa do Catecismo histórico foi um best seller até a metade do século XIX. Claude Fleury opta pelo método histórico ao escrever o catecismo, que contém um resumo da história e da doutrina cristã, pretendendo oferecer acesso ao sentido dos textos sagrados, rompendo com a prática da memorização, pela leitura, que deveria ser realizada pelas crianças nas escolas. Insere nele figuras da história sagrada além do estilo narrativo que conta com a possibilidade de "que todo mundo pode entender e guardar uma história (...). Principalmente as crianças são as mais ávidas por ela". As imagens, "escrita dos ignorantes", associadas à linguagem narrativa, possibilitam, segundo Fleury, um acesso à compreensão das verdades cristãs. "(...) Saber de cor certas palavras sem entender seu sentido não significa crer. Não é com a boca que se crê, mas com o coração [...]. Não se pode dizer que eu creio 'no ministério da Trindade' se não tenho dele nenhuma ideia, se tenho somente a memória carregada de um som de palavras, que me são tão desconhecidas quanto as de uma língua estrangeira. Ora, a linguagem escolástica é precisamente isso para todos aqueles que não a estudaram (...)". Julia, Dominique. Leituras e Contra-Reforma. In: Cavalo, G. \& Chartier, R. (Org). História da Leitura no Mundo Ocidental. Coleção Múltiplas Escritas. São Paulo: Ática, 1997. p.79-116. A notícia do relatório do inspetor em 1860 registra que a tradução é do Conselheiro Amaral Gurgel, porém, encontramos edição traduzida na Corte, em 1846, por Joaquim Jose da Silveira, para uso das escolas de Primeiras Letras do município da Corte. Biblioteca Digital da Câmara dos Deputados, Brasília. Coleção Livros Raros. Disponível em: <http://bd.camara.leg.br/bd/handle/bdcamara/22562 > Acesso em 20 de abril 2019. A versão em espanhol Catecismo historico, ó Compendio de la historia sagrada y la doctrina flagrada, e da Doctrina Christiana contém as imagens citadas por Julia, além de longo preâmbulo dedicado ao monarca e advertências sobre o fim e o uso do catecismo. Biblioteca Episcopal de Barcelona. s/d. Disponível em: $<$ https://books.google.com.br/books?id=9zZQAAAAcAAJ\&printsec=frontcover\&hl=pt-

$\mathrm{BR} \&$ source $=\mathrm{gbs}$ ge_summary_r\&cad $=0 \# \mathrm{v}=$ onepage\&q\&f=false $>$ Acesso em 20 de abril 2019.

${ }^{17}$ O Editor citado foi proprietário da Tipografia Imparcial e também Editor-Chefe do Jornal Correio Paulistano (1854-1963). Uma série de leis Provinciais demonstram as disputas entre editores de Catecismos. Registramos aqui algumas, a título de exemplo: Lei $\mathrm{n}^{\circ} 890$ de 06 de abril de 1866 - Manda adotar para o ensino religioso nas escolas públicas da Província o Catecismo confeccionado e mandado publicar em 1860 pelo finado Bispo Diocesano Dom Antonio Joaquim de Mello; Lei $n^{\circ} 966$ de 19 de julho de 1867 - Autoriza o Governo a despender a quantia de $400 \$ 000$ com a compra de dois mil exemplares do Cathecismo Brasileiro, que deverão ser distribuídos pelas escolas da Província; Lei no 036 de 28 de março de 1870 - Revoga a Lei $n^{\circ} 34$ de $1^{\circ}$ de julho de 1867, sobre o Cathecismo Brasileiro.
} 
Aparentemente, o material de leitura que mobilizou os governos e produziu concorrência (política) para fazer-se presente no cenário das escolas de primeiras letras foi o catecismo católico, portador da civilidade esperada e da moral cristã, porém, outros materiais de leitura utilizados nas escolas, sem o controle do Estado, compunha o rol de preocupações da Repartição da Instrução Pública.

A narrativa sobre a precariedade das escolas da época é relatada de modo exemplar na fala do Inspetor da Instrução Pública em 1864, ao tratar de parte dos desafios da institucionalização da instrução pública na Província:

[...] Commummente os professores não moram nas povoações onde são chamados a servir. Chegados alugam uma casa, e compram ou pedem emprestados alguns trastes, é nessa casa e com esses trastes que a cadeira vai se installar. A fora a capital, a provincia não os fornece; o professor vence ordenados diminutos. Não importa; a elle incumbe dar local e moveis e utensis. A casa necessariamente é pequena e a sala destinada ao ensino impropria por seu aspecto e dimensões. Uma mesa pequena, e um ou dois bancos velhos, eis a mobilia, feliz ainda quem os obtem. Um tinteiro, algumas pennas, meia dúzia de traslados escriptos pelo professor, sabe Deus com que erros, cartas particulares inçadas de toda sorte de defeitos, eis os utensis. Cousas indispensaveis são dispensadas. Quem ha hoje que ignore que a prosperidade das escolas essencialmente depende dos materiais e casa? ${ }^{18}$ (grifos nossos)

Os materiais de leitura a serem utilizados nas escolas de primeiras letras ganham importância crescente nos discursos do Presidente: em 1865, a leitura surge como importante ferramenta para a conformação do caráter, noticiando ter mandado imprimir a obra "Quadros Históricos da província de S. Paulo" do Sr. Brigadeiro José Joaquim Machado de Oliveira e de 1.500 exemplares para distribuir às escolas da província.

As vantagens da instrução primaria não consistem em saber ler, escrever e contar. A instrucção se não deve limitar a este estudo material; pelo contrário ella deve principalmente considerar a leitura e a escripta como meios de adquirir conhecimentos uteis, e trabalhar no aperfeiçoamento moral dos que aprendem. Debaixo deste aspecto o ensino publico necessita para produzir bons fructos ser favorecido de bons livros. A falta de conveniente leitura faz com que o espirito, cuja actividade ha sido despertada, vá beber em fontes venenosas um alimento mortifero. ${ }^{19}$. (grifos nossos)

\footnotetext{
${ }^{18}$ Relatório sobre a Instrução Pública de S. Paulo em 1864 apresentado ao Ilm. E Exm. Snr. Conselheiro João Chrispiniano Soares Presidente da Província pelo Inspetor Geral da Mesma Instrução Pública Diogo de Mendonça Pinto. Anexos do Relatório apresentado Assembléia Legislativa Provincial de São Paulo (1985) na Segunda sessão da décima Quinta legislatura pelo presidente O Conselheiro João Chrispinianno Soares S.Paulo Typ. Imparcial, de J.R. de a Marques, 49 - Rua da Imperatriz - 49.

191865 Relatório apresentado à Assembleia Legislativa Provincial de São Paulo na Segunda sessão da décima Quinta legislatura no dia 2 de fevereiro de 1865 pelo Presidente da mesma Província O Conselheiro João Chrispinianno Soares S.Paulo Typ. Imparcial, de J.R. de a Marques, 49 - Rua do Rosário - 491865.
} 
Em 1880, o Presidente anuncia ter autorizado a compra de 800 exemplares do "Novo método de ensinar a ler e escrever" do Dr. Freire, de 500 exemplares das "Lições de História Pátria" pelo Dr. Américo Brasiliense, e contratado a aquisição de 6.000 exemplares do "Compêndio de Geografia' do Dr. Jeronymo Sodré, “obra que deverá publicar em breve e em que se obrigou a tratar desta província, com mais particularidade do que o fez em seu livro já publicado."20

Os materiais de ensino, pensados como mediação entre a atividade do mestre e a aprendizagem do aluno, vinculam-se também às práticas de ensinar, ao governo do ensino; os métodos de ensino surgem como fórmulas a serem adotadas pelo professor para solucionar a aprendizagem dos alunos, formando uma das camadas do campo educativo, que desenha uma certa economia dos procedimentos para abreviar os tempos, estabelecer regularidades, disciplinar a prática do professor e do aluno. A ausência de método de ensino nas escolas é um dos argumentos constantes que justificam o estado não lisonjeiro das escolas.

Nessa rede de práticas educativas disseminadas na sociedade, as escolas primárias - nas palavras do Inspetor da Instrução Pública em 1854 - "são a partilha da multidão; as médias cabem à porção que, vivendo com certa comodidade, interessa e tem direito a ir além das primeiras letras". ${ }^{21}$ A oferta da escola primária como grande desafio imposto pela Constituição à Província de São Paulo teve por fim desasnar a infância, enquanto a instrução secundária destinou-se à mocidade que se voltava a profissões livres ou aos estudos universitários, este sim dirigido aos membros das "classes mais elevadas" onde encontrariam "a erudição e ciência precisa para reterem a influência que são chamados a exercer na Sociedade".

Nos três eventos apresentados nesse artigo: a formação da estatística da província, a introdução do inquérito policial pela Reforma Judiciária de 1871 e o uso da leitura e da escrita na regeneração moral de sentenciados, destacamos um singular universo de demandas de leitura e escrita voltados ao governo de homens e coisas, de onde podemos retirar contribuições para compreender os caminhos que levam até a escola um conjunto ímpar de expectativas que transbordam o ler, escrever, contar e se comportar, produzindo incessantemente as condições necessárias às práticas de governo.

Lembrando Chartier (1994 p.107) podemos entender que a escrita do Estado, enquanto "obra", produz uma série de operações que tendem a conformar um sentido estável; as leis e regulamentos poderiam estar no topo de uma classificação destas obras do Estado, pois tentam constranger a leitura e conformar as práticas, porém, a proliferação destas "obras" marca ao mesmo tempo o campo de resistências que exigiu permanentemente a revisão das mesmas obras em resposta às resistências e aos constrangimentos que a leitura e a prática social impõem à escrita do Estado.

Considerando a proliferação dos textos normativos e prescritivos no período, devemos considerar também os impactos que as práticas do ler e escrever sedimentam ao pensar na relação "escrita e leitura" no formato da "ordem e obediência".

[...] Por certo, os criadores, ou as autoridades, ou os "clérigos" (pertençam eles ou não à Igreja) sempre aspiram a fixar o sentido e a enunciar a interpretação correta que deve constranger a leitura (ou o olhar). Mas sempre, também, a recepção inventa, desloca, distorce. (CHARTIER, 1994, p.107)

\footnotetext{
${ }^{20}$ Interessante levantamento de utensis para escolas e o mercado editorial voltado para o ensino é compilado por Hilsdorf, Maria Lúcia Spedo. Tempos de escola: fontes para a presença feminina na Educação, São Paulo, - Século XIX. Centro de Memória da Educação - Feusp. - São Paulo: Plêiade, 1999.

${ }^{21}$ Relatório da Instrução Pública da Província no corrente ano. Diogo de Mendonça Pinto, Inspetor Geral da Instrução Pública.1854. Documentos com que o Ilustríssimo e Excelentíssimo Senhor Dr. José Antonio Saraiva, Presidente da Província de S. Paulo, instruiu o Relatório da abertura da Assembleia Legislativa Provincial no dia 15 de fevereiro de 1855. Na typografia 2 de dezembro de Antonio Louzada Antunes. 1855
} 
A proliferação de escritos do Estado - ou melhor dizendo, a proliferação dos escritos para governar - ao longo do século XIX oferece indícios importantes para investigarmos os possíveis impactos deste modelo de escrita na conformação das práticas de leitura e escrita desenvolvidas nas escolas, e esta provocação continua um exercício necessário.

\section{Referências}

BRASIL, Decreto Imperial No4.824, de 22 de novembro de 1871. http://www.planalto.gov.br/ccivil_03/decreto/historicos/dim/DIM4824.htm. Acesso em 14 de abril de 2019.

CHARTIER, R. A história cultural: entre práticas e representações. Lisboa: DIFEL/ Rio de Janeiro: Bertrand Brasil, 1990.

CHARTIER, R. A história hoje: dúvidas, desafios, propostas. Estudos Históricos, Rio de Janeiro, v.7, n13, 1994.

FERNANDES, R. Gênese e consolidação do sistema educativo nacional (1820-1910). In: $O$ sistema de Ensino em Portugal (Séculos XIX-XX). Maria Cândida Proença (Org.). Lisboa: Edições Colibri, 1998

FERNANDES, R.. Os caminhos do ABC. Sociedade Portuguesa e Ensino das Primeiras Letras. Lisboa: Porto Editora, 1994.

FOUCAULT. Michel. Vigiar e Punir: nascimento da prisão. Petrópolis: Vozes, 1987, $18^{\mathrm{a}}$ ed.

GIGLIO, C. M. B. Uma genealogia de práticas educativas na Província de São Paulo: 1836-1876. São Paulo: Feusp, 2001 [Tese de doutorado].

HILSDORF, Maria Lúcia Spedo. Tempos de escola: fontes para a presença feminina na Educação, São Paulo, - Século XIX. Centro de Memória da Educação - Feusp. - São Paulo: Plêiade, 1999.

JULIA, Dominique. Leituras e Contra-Reforma. In: Cavalo, G. \& Chartier, R. (Org). História da Leitura no Mundo Ocidental. Coleção Múltiplas Escritas. São Paulo: Ática, 1997.

REVEL, J. Conhecimento do território, produção do território: França, séculos XIII-XIX. A invenção da Sociedade. Lisboa: DIFEL; Rio de Janeiro: Bertrand Brasil. 1989.

TARCISIO R. Botelho. Censos e construção nacional no Brasil Imperial, pp. 321-341. Tempo Social, Revista de Sociologia da USP, v. 17, n. junho 2005. https://doi.org/10.1590/s010320702005000100014

\section{Fontes}

SÃO PAULO (Província). Discurso com que o Ilustríssimo e Excelentíssimo Senhor Dr. José Thomaz Nabuco 'Araujo, presidente da província de São Paulo, abiu a Assembleia Legislativa Provincial no dia 1.o de maio de 1852. São Paulo, na Typ. do Governo arrendada por Antonio Louzada Antunes, 1852. 
SÃo PAULO (Província). Relatório da Instrução Pública da Província no corrente ano. Diogo de Mendonça Pinto, Inspetor Geral da Instrução Pública.1854. Documentos com que o Ilustríssimo e Excelentíssimo Senhor Dr. José Antonio Saraiva, Presidente da Província de S. Paulo, instruiu o Relatório da abertura da Assembleia Legislativa Provincial no dia 15 de fevereiro de 1855 . Na typografia 2 de dezembro de Antonio Louzada Antunes. 1855

SÃO PAULO (Província). Discurso com que o Ilustríssimo e Excelentíssimo Senhor Senador José Joaquim Fernandes Torres, Presidente da Província de S. Paulo, abriu a Assembléia Legislativa Provincial, no dia 2 de fevereiro de 1860.

SÃO PAULO (Província). Relatório da Inspetoria Geral da Instrução Pública 31 de dezembro de 1860. Anexo ao Discurso com que o Ilustríssimo e Excelentíssimo Senhor Conselheiro Antônio José Henriques Presidente da Província de São Paulo abriu a Assembleia Legislativa Provincial no dia 2 de março de 1861.

SÃO PAULO (Província). Relatório sobre a Instrução Pública de S. Paulo em 1864 apresentado ao Ilm. E exm. Snr. Conselheiro João Chrispiniano Soares Presidente da Província pelo Inspetor Geral da Mesma Instrução Pública Diogo de Mendonça Pinto.

SÃO PAULO (Província). Relatório apresentado à Assembleia Legislativa Provincial de São Paulo na Segunda sessão da décima Quinta legislatura no dia 2 de fevereiro de 1865 pelo Presidente da mesma Província O Conselheiro João Chrispinianno Soares S.Paulo Typ. Imparcial, de J.R. de ${ }^{a}$ Marques, 49 - Rua do Rosário - 49.

SÃO PAULO (Província). Relatório da Casa de Correção. Anexo ao Relatório com que S. Exc. O Sr. Senador Barão de Itaúna passou a Administração da Província de S. Paulo, ao Exmo. Sr. Comendador Antonio Joaquim Rosa, $3^{\circ}$ Vice-Presidente [em 25 de abril de 1869].

SÃO PAULO (Província). Relatório da Repartição da Polícia da Província de São Paulo, 1871, p.4-22. Anexo ao Relatório apresentado à Assembleia Legislativa Provincial de São Paulo pelo Presidente da província, o Exm. Sr. Dr. José Fernandes da Costa Pereira Junior, em 2 de fevereiro de 1872. Paulo [sic], Typ. Americana, 1871.

SÃo PAULO (Província). Relatório da Repartição da Polícia da Província de São Paulo, 1871, p.4-22. Anexo ao Relatório apresentado à Assembleia Legislativa Provincial de São Paulo pelo Presidente da província, o Exm. Sr. Dr. José Fernandes da Costa Pereira Junior, em 2 de fevereiro de 1872. Paulo [sic], Typ. Americana.

SÃO PAULO (Província). Relatório apresentado ao Ilustríssimo e Excelentíssimo Senhor Dr. João Theodoro Xavier Presidente da Província de São Paulo, pelo Chefe de Polícia Joaquim José do Amaral, Juiz de Direito. Anexo ao Relatório apresentado à Assembleia Legislativa Provincial de S. Paulo, pelo Presidente da Província o Exmo. Sr. Dr. João Theodoro Xavier em 5 de fevereiro de 1874.

SÃO PAULO (Província). Relatório apresentado à Assembleia Legislativa Provincial de S. Paulo, pelo Presidente da Província, Sr. Dr. Sebastião José Pereira, em 2 de fevereiro de 1876.

SÃO PAULO (Província). Relatório com que o Exmo. Sr. Dr. Sebastião José Pereira passou a administração da Província ao $5^{\circ}$ Vice-Presidente, Monsenhor Joaquim Manoel Gonçalves de Andrade, em 16 de janeiro de 1878. 